\title{
LA MADUREZ TEXTUAL MEDIEVAL DE LAS LENGUAS ROMANCES
}

\author{
Michael Metzeltin \\ Universität Wien / Institut für Romanistik (Österreich) \\ michael.metzeltin@univie.ac.at
}

\section{La textualidad como madurez cultural}

La palabra madurez pertenece al área conceptual de la biología. Los seres con vida nacen, se desarrollan y mueren. De manera análoga, podríamos decir que, como niños, engendramos por imitación nuestros idiolectos que iremos desarrollando a lo largo de la vida, pero cuando desaparecemos, las lenguas como sociolectos siguen existiendo. Las lenguas son instrumentos utilizados para la cognición y la comunicación, son sistemas de signos que no nacen y no mueren, sino que son creados y continuamente transformados por los seres humanos para sus necesidades en cada momento. Sí se puede dejar de usarlas, pero pueden mantenerse más o menos latentes con un uso específico limitado, como el latín o el sánscrito litúrgicos, o, en ciertas épocas, reducidas al habla familiar, como algunas lenguas románicas, pero siempre se pueden reactivar, como en el caso del ivrit o del gallego.

Comparada con la vida de los adultos, teniendo en cuenta que las lenguas son instrumentos de cognición y comunicación, la metáfora de la madurez significaría algo como: en una sociedad desarrollada los usuarios disponen de una lengua con la cual pueden captar y expresar todas las concepciones y todos los hechos en todos los campos de sus actividades, es decir, en todos los ámbitos cognitivos y praxeológicos. Las concepciones de estas actividades tienen fundamentalmente carácter descriptivo, narrativo o argumentativo y su verbalización se cuaja en diferentes géneros textuales: los usuarios han desarrollado para su lengua la plena adecuación textual. 
Desde este punto de vista, una lengua sería potencialmente madura si en la respectiva sociedad existiesen, por lo menos en estado latente, los fundamentos lingüísticos (léxicos. morfológicos, sintácticos, textuales) necesarios para establecer los diferentes géneros textuales requeridos por los variados ámbitos de su cultura (potencialidad textual). Realmente madura sería la respectiva sociedad solo si ha conseguido desarrollar los paradigmas de los diferentes géneros textuales en series reproducibles ( $v . g r$. poemas épicos, cartas de donación, etc.; serialización textual). La riqueza de series textuales constituye uno de los ejes básicos de toda cultura. El desarrollo de series textuales está correlacionado con la formación y la continuidad de estructuras estatales. También pueden caer en desuso si su campo de aplicación se ha desactualizado (v. gr. hoy los poemas épicos).

\section{La aparición de las lenguas romances}

A través de las leyes del mínimo esfuerzo y de la máxima claridad los usuarios de una lengua la adaptan continuamente a sus respectivas necesidades, la siguen transformando. Estas transformaciones son más evidentes en épocas de crisis política, económica y social, como el período que va de la disolución del Imperio romano de Occidente a la formación del Imperio carolingio y de la monarquía astur-leonesa. En este período los cambios lingüísticos se aceleran y las variedades del latín hablado regional, tanto a nivel morfosintáctico como a nivel léxico, se distancian cada vez más del estándar formal y también entre sí hasta llegar a una ruptura tipológica con respecto al latín y a una incipiente ruptura de similitud formal y léxica de las nuevas lenguas neolatinas.

A partir del siglo IX aparecen en forma fragmentaria los primeros testimonios de las lenguas romances: palabras aisladas, sobre todo topónimos (orticello, pezza en documentos notariales italianos, s. Ix; topónimos como Kabrils, Linars, Palomera en el Acta de consagración y dotación de la catedral de Urgel, s. Ix); frases aisladas en textos latinos (Placiti campani, s. x); breves apuntes (Nodicia de kesos, León, s. x), glosas (Glosas emilianenses $y$ silenses, $\mathrm{s}$. X-XI). Hasta el siglo XII la textualización en romance es todavía muy rara. Los primeros escritos concebidos como texto en lengua romance aparecen en el siglo IX en el dominio de la lengua de oíl (Juramentos de Estrasburgo, Cantilena de Santa Eulalia); en el siglo xI en el dominio occitano (pleitos homenaje); en el siglo XII en Cataluña (Juramento de fidelidad del conde Pere Ramon de Pallars) y en Italia (Fórmula de confesión umbra) y, en el siglo XII y a principios del XIII, en tierras asturianas, leonesas, castellanas 
y portuguesas (Fuero de Avilés, 1155; Tratado de Cabreros, 1206; Cantar de mio Cid, 1207(?); Testamento de D. Afonso II, 1214). Son más bien ejemplos aislados, que en buena parte calcan patrones textuales latinos.

Las serializaciones romances solo empiezan en el siglo XII en tierras francesas y occitanas, en el XIII en los demás países románicos. Tenemos que prescindir del rumano, cuya textualización no aparece sino en el siglo XVI. Para las obras de tenor más importante como las historiográficas las series latinas se mantienen hasta el siglo XIII, como testimonian Pablo Diácono (Historia Langobardorum, s. VIII) y Hugo Falcando (Liber de regno Sicilie, s. XII) en Italia, Gregorio de Tours (Decem libri historiarum, s. VI), los autores de los Annales regni francorum (s. VIII- IX) y Ordericus Vitalis (Historia ecclesiastica, s. XII) en Francia, así como los anónimos autores del Chronicon Albeldense (s. Ix) y de la Historia compostelana (De rebus gestis D. Didaci Gelimirez, primi Compostellani Archiepiscopi, s. XII), o Lucas de Tuy (Chronicon mundi, 1236) y Rodrigo Jiménez de Rada (De rebus Hispaniae, 1243) en la Península ibérica.

\section{Una textualidad plena: el desarrollo de la serialización textual francesa}

Gran importancia para la educación cristiana medieval tiene la narración de la vida de los santos y las santas. No es por lo tanto de admirar que la hagiografía constituya la primera serialización textual en el dominio de oíl. Al siglo IX se remonta la Séquence de Sainte Eulalie (Cantilena de Santa Eulalia, h. 881), que cuenta la vida y el martirio de la santa de Mérida. En el siglo x se redacta la Vie de Saint Léger (Vida de San Leodegario, obispo de Autun), en el siglo xi la Vie de Saint Alexis (Vida de San Alejo, patrón de los mendicantes). A este género pertenece también la Vie de Saint Thomas Becket (1174) en que Guernes de Pont-Sainte-Maxence narra la historia no de un santo legendario, sino del arzobispo de Canterbury asesinado en su catedral en 1172. Al lado de esta primera literatura escrita, de tendencia sobre todo religiosa, surge a partir del siglo xI la épica con héroes del mundo franco (las chansons de geste, los cantares de gesta) que, empezando por la Chanson de Roland y la Chanson de Gormont et Isembart se desarrolla en los tres ciclos de la Geste de Charlemange, la Geste de Doon de Mayence y la Geste de Guillaume d'Orange con varias centenas de obras hasta el siglo Xv.

El siglo XII asistimos a una verdadera eclosión de géneros textuales en romance. De esta época datan las transposiciones de novelas y temas novelescos de la Antigüedad (Roman d'Alexandre, Roman de Thèbes, Roman d'Eneas, Roman de Troie) y las novelas cortesanas de Chrétien de Troyes 
en verso (Érec et Énide, Cligès, Lancelot, Perceval ou le conte du Graal) que tendrán su auge en el siglo XIII con las obras del ciclo Lanzarote-Grial en prosa. Se escriben largas crónicas versificadas (Roman de Rou de Wace, Chronique des ducs de Normandie de Benoît de Saint-Maure), pero a partir del siglo XIII la historiografía se redactará en prosa (Geoffroy de Villehardouin, De la conquête de Constantinople, 1207-1213; Primat de Saint-Denis, el Roman aux roys, h. 1275, texto que será la base de las Grandes chroniques de France). Siempre en el mismo siglo surge la lírica cortesana sobre el modelo provenzal (Chrétien de Troyes, Gace Brulé, Richard Coeur de Lion), que tendrá su codificación en el Art de dictier et de fere chançons, balades, virelais et rondeaux de Eustache Deschamps (1392). Hacia finales del siglo XII se componen las primeras piezas teatrales (el Jeu d'Adam, anónimo; el Jeu de Saint Nicolas de Jean Bodel, 1200) y también se inicia el discurso moral-filosófico (Roman de philosophie de Simon de Freine).

En el siglo XIII aparecen los cuentos costumbristas y moralizantes ( $f a-$ bliaux) y el romance empieza a usarse también en los textos didáctico-científicos (Image du monde de Gautier de Metz, 1245, una elaboración de la cosmografía Imago mundi de Honorius de Autun del siglo XII). Hacia mediados del siglo XIII el romance se impone asimismo en los instrumentos notariales, a partir de 1256 también en las leyes emitidas por los reyes (lettres, mandements, ordonnances, édits), aunque el latín se sigue usando en la comunicación con los países de lengua de oc. Étienne Boileau reúne en los Établissements des métiers de Paris (1268) los reglamentos de los gremios de artesanos y Felipe de Beaumanoir concluye en 1283 la compilación Coutumes et usages du Beauvaisis, considerada como la expresión más acabada de la herencia jurídica del reinado de Luis IX.

De esta manera, en el arco de cinco siglos, el francés ha podido ser adaptado a todos los mundos discursivos y utilizado para todos los géneros textuales, a pesar de que el latín sigue siendo usado en los dominios jurídicos y científicos hasta el siglo XVI, cuando las reales órdenes establecen el uso del francés en la jurisprudencia y el cirujano Ambroise Paré lo usa en medicina.

\section{Una textualidad sofocada: el desarrollo de la serialización textual occitana}

Las tierras occitanas presentan en la Edad Media una gran fragmentación política. En el siglo XI la parte oriental (hasta el Ródano) pertenece al reino de Borgoña, parte integrante del Sacro Imperio, mientras que la parte occidental constituye el ducado de Aquitania, vasallo del rey de Francia. Este ducado 
está dividido en más de diez feudos, entre los cuales destacan el condado de Tolosa y el ducado de Gascuña. Pero si esta fragmentación se ha reflejado en la formación de diferentes variedades dialectales, no ha impedido la concienciación de una lengua escriptural común que se reflejará en los manuales de gramática y de poética de los siglos XIII y XIV.

La serialización textual aparece desde el siglo XI. En 1059 empieza la serie textual de los pleitos homenaje redactados completamente en romance. En 1102 comienza la serie de instrumentos notariales de transacción de bienes (compraventa, donación, testamento). Al siglo XII se remonta la tradición de poemas épicos y novelas de aventuras en verso (Alexandre, Cançon d'Antiocha, Daurel et Beton, Girard de Rossellon, Jaufre), documentada hasta el siglo XIV (Arnaud Vidal de Castelnaudari, Guilhem de la Barra, 1318), como también la redacción de importantes textos jurídicos (Lo Codi, una adaptación del Codex Justinianus; las Costumas de Sent Gaudens). Pero el occitano cobra su máximo esplendor gracias a las centenas de trovadores que entre los siglos XII y XIV cantan el amor cortés en varias formas líricas (cansó, planh, tensó, pastorela, alba) o escriben sirventeses satíricos sobre temas morales o políticos. Entre ellos destacaron Guillermo VII de Poitiers y IX de Aquitania (Guilhem de Peitieus, 1071-1127), el primer trovador conocido, Jaufre Rudel, Marcabrú, Bernart de Ventadorn, Guiraut de Bornelh, Arnaut Daniel, Bertran de Born, Peire Vidal, etc. Algunos trovadores actúan en cortes extranjeras, como Raimbaut de Vaqueiras (h. 1155-1207) en la corte de Bonifacio I de Monferrato o Guiraut Riquier (h. 1230-1292) en la corte de Alfonso X el Sabio. Pero también surgen poetas extranjeros que escriben en occitano, como los catalanes Guillem de Berguedà (siglo XII), Raimon Vidal de Besalú (h. 1160-1220) y Guillem de Cervera (Cerverí de Girona, siglo XIII) o los italianos Sordello (h. 1200-1270) y Bonifacio Calvo (h. 1230-1300). La alta consideración de que goza la poesía provenzal es confirmada no sólo por su imitación en Francia, Galicia, Portugal y Alemania, sino también por la redacción de gramáticas y artes poéticas que enseñan el recto uso de la lengua y de la construcción de versos y estrofas: Raimon Vidal de Besalú escribe hacia 1190-1213 las Razos de trobar «per far conoisser et saber qal dels trobadors an mielz trobat et mielz ensenhat ad aqelz qu.1 volran aprenre con devon segre la dreicha maniera de trovar»; Uc Faidit compone en Italia hacia 1240 un Donatz proensals; Jofre de Foxà escribe hacia 1286-1291 por mandato de Jaime II, rey de Sicilia, unas Regles de trobar; y en el siglo XIV (1328-1337) Guilhem Molinier redacta las Leys d'amors, el código gramatical y poético de la escuela de Tolosa. 
Pero debido a las guerras contra los albigenses (1202-1229) y contra los ingleses (Guerra de los Cien Años, 1337-1453) y a una hábil política dinástica, los reyes de Francia consiguen reintegrar a la Corona entre los siglos XIII y xv los feudos occitanos. En la administración se impone poco a poco el francés que sustituye el occitano también en la literatura.

\section{Una textualidad potencial: el desarrollo de la serialización textual catalana}

Unas primeras serializaciones textuales aparecen en las tierras catalanas ya en los siglos XI y XII con los numerosos pleitos homenaje, muchas veces redactados en un romance latinizado, y con las cartas de agravio, como la Memoria de Guitart Isarn, señor de Caboet (1080-1095). También se puede considerar texto serializado la colección de sermones conocida como las Homilies d'Organyà de origen occitano (h. 1200). A partir del siglo XIII la lengua vernácula se impone en la historiografía (traducción de las Gesta comitum barcinonensium et regum Aragoniae, Libre dels fets del rey Jaume I, Libre del rei en Pere de Bernat Desclot, serie continuada en el siglo XIV por la Crònica de Ramon Muntaner y la Crònica de Pere el Cerimoniós) y en la jurisprudencia (en las colecciones de leyes Usatges de Barcelona, Commemoracions de Pere Albert, Furs de València, Costums de Tortosa, Llibre del consolat de mar, de los cuales existe, en general, una primera redacción más antigua en latín). En la extensa obra polifacética y enciclopédica de Ramon Llull (1232/1234-1316), escrita en latín, catalán, provenzal y árabe, podemos encontrar el potencial tanto formal como temático para formar series textuales. Así el Llibre d'Evast e d'Aloma e de Blanquerna son fill (1283) propone un paradigma de novela, mientras que el Llibre de les bèsties, contenido en el Fèlix o Llibre de meravelles (1287-1289) ofrece la estructura de un fabulario. Algunos de los 16 árboles del Arbre de ciència (1295-1296) podrían servir de base para tratados de geofísica, botánica o política. Un potencial parecido lo hubiera ofrecido la obra médica latina de Arnau de Vilanova (ca. 12401313), de la cual solo el Regimen sanitatis ad regem Aragonum (1303-1308) fue vertido al catalán (Regiment de sanitat per al rei d'Aragó, antes de 1310). $\mathrm{Si}$ asistimos todavía a un notable florecimiento de algunos géneros (sobre todo en el siglo xv) como las novelas Curial e Güelfa, anónima, y el Tirant lo Blanc de Joanot Martorell y Martí Joan de Galba, la orientación cada vez más peninsular a partir de la entronización de la casa castellana de los Trastámara por el Compromiso de Caspe (1412) conllevará una larga latencia de las serializaciones textuales catalanas hasta el siglo XIX. 


\section{Una textualidad transregional: el desarrollo de la serialización textual italiana}

Entre los siglos x y XIII buena parte de la Península apenina forma parte, como Regnum italicum, del Sacro Imperio Romano Germánico, pero los emperadores no consiguen unificar el reino. A sus esfuerzos se oponen cada vez más los señores feudales y las ciudades, creando, con el tiempo, fuertes poderes regionales. La plurisecular fragmentación política de Italia se refleja en la gran variedad lingüística. A principios del siglo XIV, Dante retiene en su De vulgari eloquentia (I, x) la existencia de 14 dialectos regionales a la derecha y a la izquierda de la cadena de los Apeninos. Gracias a la formación de varios Estados más o menos independientes, para algunos de estos dialectos se ha desarrollado ya desde la Edad Media una conciencia lingüística y una variante literaria. En el Piamonte se redactan en los siglos XII-XIII los anónimos Sermoni subalpini. En Lombardía, Bonvesin da la Riva (h. 12401314) escribe en versos romances contrastos, leyendas hagiográficas y obras didácticas. Giacomino da Verona compone hacia 1275 dos poemas didácticos en romance veronés (De Babilonia civitate infernali y De Jerusalem celesti). También al siglo XIII se remontan las anónimas Storie de Troja et de Roma, romanceamiento en dialecto romanesco de un texto latino. Y de la misma época son las poesías de la Escuela siciliana de la Corte de Federico II (1194-1250).

Pese a que la unidad política de Italia solo se consiguió en el siglo XIX, siempre existió la conciencia de Italia como una unidad desde los Alpes hasta Sicilia, basada en la unidad administrativa de las 11 regiones creada por los romanos. Consecuentemente Dante Alighieri opina en el ya citado De vulgari eloquentia que los italianos (Ytali, Latini) constituyen una nación (natio, gens: I, viii) que necesita un idioma literario «vulgar» común. Este vulgare debería ser illustre (es decir, sublimado por el magisterio, el poder, el honor y la fama), cardinale (alrededor de él deberían girar las numerosas lenguas de los municipios, como las puertas siguen a sus goznes), aulicum (si los italianos tuvieran una corte real sería la lengua palaciega) y curiale (equilibrado en la sede del poder administrativo (I, xvii-xviii). El gran poeta cree poder identificar el vulgar ilustre, la nueva lengua guía, en el toscano literario elaborado por los poetas del dolce stil nuovo (Guido Guinizelli, Guido Cavalcanti, Cino da Pistoia, el mismo Dante, etc.). La lengua del dolce stil nuovo junto a la lengua de los tres grandes toscanos de los siglos XIII-XIV -las tres coronas Dante Alighieri (1261-1321), Francesco Petrarca (1304-1374), 
Giovanni Boccaccio (1313-1375) - constituirán la base del italiano literario y de la futura lengua nacional.

Las series textuales romances, a veces precedidas por versiones latinas, se constituyen en diferentes épocas: sonetos y canciones, a partir del siglo XIII (poetas de la corte de Federico II, Guittone d'Arezzo, los poetas del dolce stil nuovo, Petrarca, etc.); estatutos municipales, a partir del siglo XIII (Breve di Montieri, 1219, Statuti della Lega di Chianti, 1384, etc.); documentos notariales, a partir de mediados del siglo XIII; crónicas, a partir del siglo XIII (Ricordano y Giacotto Malispini, Dino Compagni, Giovanni y Matteo Villani, Machiavelli, Guicciardini); derroteros (en italiano portolani), a partir de mediados del siglo XIII (Lo compasso de navegare, etc.); ensayos y manuales científicos, a partir de la segunda mitad del siglo XIII (Ristoro d'Arezzo, $L a$ composizione del mondo, 1282; Leon Battista Alberti, Della pittura, 1436, etc.); biografías y autobiografías, a partir de fines del siglo XIII (Dante, Vita nuova, Giorgio Vasari, Benvenuto Cellini); cantares, poemas épicos y de caballerías, a partir del siglo XIV (Cantare di Florio e Biancifiore; Boccaccio, Teseida; Andrea da Barberino, Reali di Francia; Luigi Pulci, Morgante; Matteo Maria Boiardo, Orlando innamorato, etc.); cuentos, a partir del siglo XIV (Boccaccio, Franco Sacchetti, Giovanni Sercambi, Gian Francesco Straparola, Matteo Bandello, etc.); fábulas, a partir del siglo XIV (Esopo volgare, Agnolo Firenzuola, etc.); las sacre rappresentazioni (teatro religioso, siglos XIV-XV); novelas y dramas pastoriles (de fines del siglo XV hasta el siglo XVII: Iacopo Sannazaro, Arcadia; Torquato Tasso, Aminta, etc.).

En el ambiente toscano y boloñés surgen también las primeras obras que enseñan cómo se pueden escribir textos y, por lo tanto, reproducir sus paradigmas: Guido Faba propone en su Gemma purpurea (1237) y en los Parlamenta (h. 1243) ejemplos de epístolas y discursos en romance y Dante Alighieri en su De vulgari eloquentia (h. 1305, inacabado) describe la estructura del género textual de la canción.

\section{Una textualidad marginal: el desarrollo de las serializaciones textuales gallega y portuguesa}

Galicia estuvo en general ligada a la monarquía astur-leonesa. Fue reino independiente solo durante breves períodos, normalmente por motivo de repartos dinásticos (bajo Ordoño II, 910-914; bajo Sancho I, 926-929; bajo el hijo menor de Fernando I, García, 1065-1071; bajo Alfonso Raimúndez, 1111-1126). Pero por razones administrativas, religiosas y lingüísticas al mismo tiempo mantuvo siempre una personalidad propia. Alfonso VI había 
concedido Galicia como condado a su hija Urraca y a su esposo Raimundo de Borgoña, que desde 1092 ostenta el título de totius Gallecie princeps. A partir del siglo XII la organización del territorio está dominada por la institución de los foros locales. Sobre todo a partir del siglo XI, Santiago de Compostela con su catedral que, según la tradición, guarda la tumba del Apóstol Santiago, es uno de los tres grandes centros cristianos de peregrinación. A partir del siglo XIII, con la constitución de la Corona de Castilla y el desarrollo de esta hacia el sur, Galicia queda políticamente cada vez más marginada, aunque mantiene la denominación de Reino. Hasta Fernando III se respetó la convocatoria de Cortes separadas de León y Galicia, por un lado, y de Castilla por otro, pero Alfonso X convoca las Cortes de los tres reinos conjuntamente y nunca en Galicia.

A finales del siglo XI, el rey Alfonso VI de León entregó el gobierno de las tierras del condado de Galicia situadas entre los ríos Miño y Tajo a Ramón Enrique de Borgoña para recompensarle por los servicios prestados en la guerra contra los almorávides. Es probable que se tratara al mismo tiempo de una donación a la infanta bastarda del rey, Teresa, con motivo de su boda (1093) con el noble borgoñón. Surge así el Condado Portucalense, núcleo del futuro reino de Portugal, regido por los dos esposos hasta 1112 y por la viuda hasta 1128. La corte reside hasta 1147 en Braga. El sentimiento de una nueva identidad territorial es apoyada por la restauración del obispado de Braga (sobre 1170), transformado en los primeros años del siglo XIII en arzobispado y metrópoli.

Los esfuerzos de la condesa Teresa y de los primeros reyes (D. Afonso Henriques, 1128-1185; D. Sancho I, o Povoador, 1185-1211; D. Afonso II, o Rei Legislador, 1211-1223; D. Sancho II, 1223-1248; D. Afonso III, o conde de Bolonha, 1248-1279) se dirigen sobre todo a asegurar la frontera con el reino de León, a reconquistar las tierras en el sur todavía en poder de los moros y a afirmar la propia realeza. Con el Tratado de Zamora (1143) el rey leonés Alfonso VII reconoce la existencia de un reino portugués y renuncia a las obligaciones de vasallaje por parte de Afonso Henriques; el papa Alejandro III le concede a éste en 1179 el título de rey. Ya en 1140 Afonso Henriques había firmado por primera vez un documento con la fórmula «Ego Alfonsus portugalensium Rex». En 1147 es reconquistada Lisboa, que se transformará poco a poco en capital política y económica del reino, mientras que Braga mantendrá la supremacía espiritual.

Pese a estos avatares de separación política, el Descort plurilingüe del poeta provenzal Raimbaut de Vaqueiras, escrito entre 1197 y 1201, con una estrofa en un gallego artificial, nos revela que en la segunda mitad del siglo 
XII se había formado en el Noroeste ibérico una koiné literaria común gallegoportuguesa para fines poéticos. Gallegos, portugueses (hasta mediados del siglo XIV) y castellanos (hasta finales del siglo Xv) la usarán como medio de expresión para la lírica amorosa (cantigas de amigo, cantigas de amor) y la sátira (cantigas de escarnio). El fondo semántico es más bien popular, pero la elaboración formal apunta localizaciones más bien cortesanas. Sobre todo en las cortes de D. Afonso III (1248-1279) y de D. Dinis (1279-1325) de Portugal y de Alfonso el Sabio (1252-1284) se producen así verdaderas serializaciones de cantigas, repartidas por centenas y centenas de textos, recogidos en buena parte en los Cancioneiro da Ajuda, Cancioneiro da Vaticana y Cancioneiro da Biblioteca Nacional. En cambio, el potencial de serialización de la poesía mariana compuesta en la corte de Alfonso el Sabio, pese a sus más de 400 cantigas narrativas de milagros y de loores a la Virgen (Cantigas de Santa María) no tuvo continuación serial. Y la separación política entre el Reino de Galicia y el Reino de Portugal llevó además a cierta distanciación entre el gallego y el portugués.

Si prescindimos de esta muy particular eclosión lírica, la textualización gallega y portuguesa consta hasta el siglo XV ante todo de textos notariales y de adaptaciones de textos traducidos.

El gallego mismo tuvo que retroceder a partir del siglo XIV frente a la paulatina castellanización de la vida pública. A partir de mediados del siglo XIII hasta principios del siglo XVI abundan, sin embargo, los documentos notariales redactados en gallego. La prosa narrativa, en cambio, sólo aparece en obras esporádicas, en general traducidas, como la General estoria (traducción del castellano, primera mitad del siglo XIV), la Crónica troyana (traducción del francés, segunda mitad del siglo xIV) y los Miragres de Santiago (traducción del latín, primera mitad del siglo xv).

Las primeras colecciones de textos en tierras portuguesas están representadas por los cartularios (v. gr. el Livro de Mumadona de la Colegiata de Guimarães, del siglo XII, o el Liber fidei sanctae bracarensis ecclesiae, de los siglos XIII-XIV). Las cartas de estas series están escritas primero en un latín bárbaro y sólo a partir del reinado de D. Afonso III (1248-1279) se empieza a usar el portugués más corrientemente en la redacción de documentos. El segundo género textual que surge en Portugal está constituido por los fueros (forais, foros), documentos mediante los cuales el rey o un señor concede a una colectividad el dominio de un territorio que aquella debe poblar, cultivar y defender, con exención de ciertas obligaciones penosas y fijación de tributos y prestaciones Los primeros fueros aparecen bajo el conde D. Henrique (1096-1112). Hasta la segunda mitad del siglo XIII, también estos textos están 
escritos en un latín simplificado. A partir de fines del siglo XIII los fueros se vierten al portugués (como los Foros de Santarém) o se redactan directamente en romance (como los Foros de S. Martinho dos Mouros, del siglo xIV). Las leyes generales del reino se empezaron a compilar por mandato del rey D. João I (1385-1433), compilación que se dio por terminada en 1446-1447 y que lleva el título de Ordenações Afonsinas.

En la corte de D. Dinis, el Rei Letrado (1279-1325), se prepararon la versión del Fuero Real de Alfonso el Sabio, las versiones parciales de las Siete Partidas del mismo rey y las traducciones de novelas francesas en prosa del ciclo artúrico (Demanda do Santo Graal, José de Arimateia, Tristão, Merlim). El mismo rey mandó traducir el texto historiográfico árabe de interés hispánico de Ahmad al-Razi (889-955), conocido bajo el título de Crónica do Mouro Rasis. En general, los siglos XIV y XV se caracterizan por una intensa actividad de traducción, llevada a cabo sobre todo en los monasterios de Santa Cruz de Coimbra y de Alcobaça y en la corte de los primeros reyes y príncipes de Avís. Pero una serialización textual autóctona solo aparece con los grandes cronistas del siglo XIV (Fernão Lopes, h. 1380-1460: Crónica de El-Rei D. Pedro, Crónica de El-Rei D. Fernando, Crónica de El-Rei D. João), Gomes Eanes de Zurara (h. 1420-1474: Crónica da Tomada de Ceuta, Crónica dos Feitos da Guiné, Crónica do Conde D. Pedro de Meneses) y Rui de Pina (1440-1522: Crónica de El-Rei D. Afonso V, Crónica de El-Rei D. João II).

\section{Una textualidad regia: el desarrollo de la serialización textual castellana}

En Castilla, las serializaciones textuales empiezan a aparecer en el siglo XIII, pero en parte se fundan en modelos latinos (como las cartas notariales y las crónicas). Otros géneros son totalmente nuevos (como el mester de juglaría). Algunos géneros desaparecen a fines de la Edad Media (mester de juglaría, mester de clerecía). Otros surgen muy tarde (como los géneros líricos o la novela sentimental). Un papel de primer orden para la creación de una textualidad serial se debe a la labor de los escritorios de Fernando III y sobre todo de Alfonso el Sabio, determinante en el dominio notarial, jurídico, didáctico e historiográfico.

Los documentos notariales (actas de compra y venta, de donación, etc.) son los primeros textos, escritos en latín, que aparecen en los reinos cristianos ya en el siglo Ix. En Castilla, la lengua vernácula se impone en la segunda mitad del siglo XIII. Para todo el territorio de habla castellana existen en todos los siglos de la Edad Media miles y miles de cartas notariales. Alfonso 
el Sabio, fundándose en tradiciones anteriores, distingue en sus Partidas (III, xviii) varios tipos de escrituras (preuillejo, carta plomada, carta de legitimación, carta de quitamiento de portadgo, carta de pagamiento, carta de auenencia, carta de encomienda, carta de vendida, carta de cambio, carta de donacion, etc.) y para cada uno de ellos propone un modelo de estructuración $\mathrm{y}$ de formulación seriales.

Los fueros definían en su origen los derechos y las obligaciones de los pobladores sobre todo de tierras reconquistadas (repartición, cultivo y defensa de la tierra, penas por delitos, privilegios). Eran concedidos en general por el rey. Las disposiciones se presentan en forma de artículos (títulos) sueltos en numeración continua. Aparecen en forma latina en el siglo x. El fuero medieval más importante fue el Forum Conche (Fuero de Cuenca), otorgado por Alfonso VIII en 1189-1190, seguido como modelo para otras muchas ciudades (Haro, Alarcón, Alcalá, Baeza, etc.). A partir del reinado de Fernando III los fueros son romanceados (Fuero de Zorita de los Canes, 1218) y contribuyen así notablemente a la formación del lenguaje jurídico castellano. Con las Siete partidas de Alfonso el Sabio empieza una tendencia de centralización que acaba en el siglo Xvi con la abrogación de los fueros.

Desde el siglo XII hay testimonios de cantares recitados por juglares, que exaltan las proezas de héroes populares (cantares de gesta, mester de juglaría). Sin embargo, pocos de estos textos han llegado a tener una forma escrita. La obra más destacada de este género es el Poema de mio Cid, conservado en un manuscrito del siglo XIV, en una versión compuesta probablemente en 1207. Se conservan además unos cien versos del Cantar de Roncesvalles (una imitación de la Chanson de Roland, de procedencia navarra; manuscrito del siglo XIV) y unos mil versos de las Mocedades de Rodrigo (sobre la juventud del Cid; manuscrito del siglo Xv). Sobre la figura del conde castellano Fernán González que se enfrenta al rey de León existe un cantar de gesta en cuaderna vía del siglo XIII (Poema de Fernán González).

En el siglo XIII surge con el Libro de Apolonio y el Libro de Alexandre el mester de clerecía. Se trata de una manera culta (de «clerecía») de escribir sobre los temas más variados (temas clásicos como la vida de Alejandro Magno, vidas de santos, proezas épicas, historias amorosas, etc.), utilizando sistemáticamente la cuaderna vía, estrofa de cuatro versos alejandrinos (de catorce sílabas) monorrimos consonantes, con pausa en medio. Escribieron en cuaderna vía Gonzalo de Berceo (h. 1196-1252), el Arcipreste de Hita (h. 1295- h. 1352: Libro de buen amor) y el Canciller Pero López de Ayala (1332-1407: Libro rimado de Palacio, compuesto entre 1385 y 1403). El mester de juglaría y el mester de clerecía tienen su ocaso ya en el siglo XIV. 
A partir del siglo XII se propagan en la Península Ibérica los apólogos de origen oriental. La primera colección se debe a un judío converso de Huesca, Pedro Alfonso (h. 1075 - d. 1130), que, hacia 1110-1120, recoge en su Disciplina clericalis 34 exempla, que tratan, entre otras cosas, de los vicios y las virtudes y de las relaciones del hombre con sus semejantes. Las enseñanzas ofrecidas se destinaban sobre todo a los predicadores, que necesitaban de ejemplos didácticos para sus sermones. A lo largo de los tres últimos siglos de la Edad Media surgen varias colecciones de fábulas en castellano inspiradas indirectamente en fuentes orientales. La primera es el Calila e Digna (Di(m) $n a)$, traducción del Panchatantra sánscrito mandada hacer probablemente por Alfonso el Sabio hacia 1251 a través de la versión árabe. Nos presenta fundamentalmente normas de conducta, ejemplificadas por apólogos, destinadas en un principio a la enseñanza de los príncipes. Los protagonistas son a menudo animales. En el Libro de los engaños e los asayamientos de las mugeres (o Sendebar), traducido del árabe por mandato de don Fadrique, hermano de Alfonso el Sabio, en 1253, encontramos una serie de cuentos integrados en un marco novelístico. En los Castigos e documentos para bien vivir, compuestos hacia 1292-1293 y atribuidos a Sancho IV, serie de consejos para el futuro monarca Fernando IV, van insertados varios apólogos de origen oriental. Una de las cumbres de este género es el Libro de los enxiemplos del Conde Lucanor et de Patronio, escrito por el Infante Don Juan Manuel entre 1328 y 1335.

Probablemente inspirado por las obras historiográficas de Lucas de Tuy y de Rodrigo Jiménez de Rada, Alfonso el Sabio emprende hacia 1270 con un grupo de colaboradores una enorme recopilación de materiales, que son sistematizados cronológicamente en la Estoria de Espanna (Primera crónica general, PCG; desde Moisés hasta Fernando III) y en la General estoria (esta última concebida como historia universal), ambas sin terminar. La obra alfonsí tuvo una repercusión enorme durante toda la Edad Media: fue repetidamente abreviada, refundida, actualizada. Así existen una Segunda crónica general (o Crónica de 1344, versión castellana de la Crónica geral de Espanha del portugués Pedro de Barcelos, esta ya una prolongación de la historia alfonsí), una Tercera crónica general (redactada en el primer cuarto del siglo XIV con materiales alfonsíes sin compilar y publicada en 1541 por Florián de Ocampo) y una Cuarta crónica general (de hacia 1460). Alfonso XI (1311-1350) promovió también la compilación de los hechos de su tiempo: su canciller Fernán Sánchez de Valladolid redacta 1344 la primera gran crónica particular de un rey (Crónica de Alfonso XI), cuyo original se ha perdido, pero del que se conocen varias versiones. En la tradición de las crónicas 
reales basadas en informaciones personales se inserta el otro gran historiador medieval, el Canciller de Castilla, Pero López de Ayala (1332-1407), con sus cuatro crónicas (Crónica de Pedro I, Crónica de Enrique II, Crónica de Juan I, Crónica de Enrique III).

Con la colección de tratados astronómicos y astrológicos de los Libros del saber de Astronomía y el Lapidario Alfonso el Sabio funda también la textualidad científica. Otros géneros textuales son más tardíos, como las novelas caballerescas (Historia del cavallero de Dios que avía por nombre Zifar, el qual por sus virtuosas obras et azañosas fue rey de Mentón, escrito entre 1300 y 1305), la poesía cancioneril, recogida en el Cancionero de Juan Alfonso de Baena (h. 1445), los romances, atestiguados en el siglo xv, pero que empiezan a recogerse solo en el siglo XVI (Cancionero general de Hernando del Castillo, 1511). Hay pocos rastros del teatro litúrgico. Si es verdad que uno de los primeros textos vernáculos es el Auto de los Reyes Magos del siglo xII, no volvemos a encontrar ningún texto escrito hasta la segunda mitad del siglo xv (Representación del nacimiento del Nuestro Señor, de Gómez Manrique, entre 1458 y 1481; Auto de la Pasión de Alonso del Campo, entre 1486 y 1499).

\section{A modo de conclusión}

Para la consolidación de una lengua como instrumento de cognición y de organización política, social y económica de una determinada cultura es importante que se desarrollen diferentes tipos textuales que sepan transmitir saberes y emociones en sus más variados aspectos.

Si comparamos el nacimiento y el desarrollo de las textualidades en las culturas románicas de la Plena Edad Media podemos comprobar que Francia consigue una gran gama de serializaciones textuales, seguida por Castilla, aunque con cierto retraso para algunos tipos textuales. Estos resultados se deben, entre otros motivos, a los impulsos directos e indirectos del rey francés Luis IX y de los reyes castellanoleoneses Fernando III y Alfonso X. Las presiones políticas coartaron la evolución de la textualidad occitana, catalana y gallega, que solo se recupera a partir del siglo XIX. El aislamiento marginal de Portugal está en el origen de su textualidad tardía. En cambio, la descentralización política de Italia y la simultánea presencia de fuertes poderes regionales han permitido a los italianos desarrollar una muy variada textualidad serializada transregional de molde toscano. 


\section{Referencias bibliográficas}

Alvar, Carlos, José-Carlos MaIner y Rosa Navarro (2014), Breve historia de la literatura española. Madrid: Alianza.

Bastardas, Reina y José Enrique Gargallo (coords.) (2007), Manual de lingüistica románica. Barcelona: Ariel.

Berschin, Helmut, Josef Felixberger y Hans Goebl (1978), Französische Sprachgeschichte. München: Max Huber.

BRunel, Clovis (1922), «Les premiers exemples de l'emploi du provençal dans les chartes», Romania, 191, pp. 335-364.

Cecchi, Emilio y Natalino SAPEgno (dirs.), (2001). Storia della letteratura italiana. Milano: Garzanti.

FrAnK, Barbara y Jörg HARTMANN (eds.) (1997), Inventaire systématique des premiers documents des langues romanes, 5 vols. Tübingen: Narr.

Holtus, Günter, Michael Metzeltin y Christian Schmitt (eds.) (1988-2005), Lexikon der Romanistischen Linguistik (LRL). Vols. I-VIII. Tübingen: Niemeyer. En particular: vol. IV (1988) para el italiano; vol. V:1 (1990) para el francés; vol. V:2 (1991) para el occitano y el catalán; vol. VI:1 (1992) para el castellano y el asturiano; y vol. VI:2 (1994) para el gallego y el portugués.

LoRENZo VÁzQUEZ, Ramón (2004), «Emerxencia e decadencia do galego escrito (séculos XIII-XVI)», en Rosario Álvarez Blanco, Fernando Fernández Rei y Antón Santamarina Fernández (eds.), A lingua galega: historia e actualidade. Santiago de Compostela: Consello da Cultura Galega/Instituto da Lingua Galega, vol. 3, pp. 27-153.

Massot, Josep (1980), La literatura de l'edat mitjana a la renaixença. Vol. 1. Montserrat: Abadia de Montserrat Publicacions.

Metzeltin, Miguel (2004), Las lenguas románicas estándar. Historia de su formación y de su uso. Oviedo: Academia de la Llingua Asturiana.

QuenEAU, Raymond (dir.) (1978), Histoires des littératures. III. Littératures françaises, connexes et marginales. Paris: Gallimard.

Russell-Gebbett, Paul (1965), Medieval Catalan Linguistic Texts. Oxford: Dolphin.

SARAIVA, António José y Óscar Lopes (2001), História da literatura portuguesa. Porto: Porto Editora. 


\section{LA MADUREZ TEXTUAL MEDIEVAL DE LAS LENGUAS ROMANCES}

Resumen: De manera metafórica, una lengua se puede considerar potencialmente madura si en la sociedad respectiva existen, por lo menos en estado latente, los fundamentos lingüísticos (léxicos. morfológicos, sintácticos, textuales) necesarios para establecer los diferentes géneros textuales requeridos por los varios ámbitos de su cultura (potencialidad textual). Realmente madura sería la respectiva sociedad solo si ha desarrollado los paradigmas de los distintos géneros textuales en series reproducibles (v. gr. poemas épicos, cartas de donación, etc.; serialización textual). La riqueza de series textuales constituye uno de los ejes básicos de toda cultura. El desarrollo de series textuales está correlacionado con la formación y la continuidad de estructuras estatales. El presente trabajo ofrece un breve panorama comparativo sobre el desarrollo textual en las diferentes culturas románicas medievales.

Palabras-Clave: Textualidad. Serialización textual. Potencialidad textual. Madurez textual. Serie textual.

\section{Medieval teXtual maturity of Romance Languages}

ABSTRACT: Metaphorically, a language can be considered potentially mature if in the respective society exist, at least in a latent state, the linguistic fundamentals (lexical, morphological, syntactic, textual) necessary to establish the different textual genres required by the various spheres of its culture (textual potentiality). The respective society would be really mature only if it has developed the paradigms of the different textual genres in reproducible series ( $v$. gr. epic poems, donation letters, etc.; textual serialization). The wealth of textual series constitutes one of the basic axes of any culture. The development of textual series is correlated with the formation and continuity of state structures. This work offers a brief comparative overview of textual development in different medieval Romance cultures.

KeYwords: Textuality. Textual serialization. Textual potentiality. Textual maturity. Textual series. 